\title{
Evolução recente da educação de pessoas adultas na Espanha*
}

Maria Clara Di Pierro**

RESUMO: O artigo relata o desenvolvimento da educação de pessoas adultas na Espanha desde seus antecedentes no século XIX aos dias atuais, enfatizando as inovações introduzidas pela reforma de ensino promovida nos anos 80 e consolidada na Lei de Organização Geral do Sistema de Ensino de 1990. São analisadas as influências exercidas neste processo pelos movimentos de renovação pedagógica, organismos internacionais e multilaterais europeus. Dentre as inovações analisadas, destacam-se: a superação da concepção de educação compensatória que historicamente presidiu a educação de pessoas adultas e sua substituição por um paradigma de educação continuada; a descentralização educativa em favor das comunidades autônomas; a preeminência do princípio político-pedagógico da integração; a adoção do território como unidade de planejamento da oferta educativa.

Palavras-chave: Educação de adultos, políticas educacionais, Espanha.

\section{Evolução recente da educação de pessoas adultas na Espanha}

Enquanto na América Latina a educação de jovens e adultos continua ocupando lugar marginal nas políticas educacionais, a relevância

* O artigo é um dos produtos do estágio de pesquisa realizado na Universidade de Barcelona entre 1997 e 1998, como bolsista da Capes (Coordenadoria de Aperfeiçoamento do Pessoal do Ensino Superior). O trabalho foi apresentado originalmente ao Grupo de Estudos de Educação de Adultos na 21aㅡ Reunião Anual da Anped - Associação Nacional de Pós Graduação e Pesquisa em Educação (Caxambu, MG: setembro de 1998).

** Mestre e Doutoranda em Educação pela Pontifícia Universidade Católica de São Paulo. Colaboradora de Ação Educativa - assessoria, pesquisa e informação. E-mail: acaoeduca@originet.com.br 
adquirida por este campo educativo nos países europeus no período recente convida à reflexão.

Sem a pretensão de abarcar a amplitude e diversidade de tradições e experiências em curso na Europa, este texto propõe-se divulgar junto aos educadores brasileiros alguns aspectos do desenvolvimento que a educação de pessoas adultas (EPA) sofreu na Espanha nos anos recentes. O empreendimento espanhol de revalorização e reforma da EPA parece especialmente sugestivo, pois se realiza em um contexto peculiar de democratização política, reconhecimento da diversidade nacional da sociedade e esforço econômico e cultural por integrar-se à União Européia, superando as carências sociais que a colocavam em posição desvantajosa no contexto regional.

Embora tenha experimentado um acentuado crescimento econômico nas últimas décadas, a Espanha legou da ditadura franquista, entre outras seqüelas, um sistema educacional anacrônico e acentuados déficits de escolarização. A reforma educativa empreendida na transição dos anos 80 e consolidada na Lei de Organização Geral do Sistema de Ensino (Logse) de 1990 procurou responder com uma formação básica ampliada, ${ }^{1}$ simultaneamente, às necessidades de elevação do nível de instrução da população, atualização e qualificação do sistema de ensino, a fim de preparar a população para participar de uma cidadania democrática em um Estado progressivamente descentralizado, uma sociedade multilíngue e culturalmente plural. Ao fazêlo, teve que responder ainda aos desafios da revolução científico-tecnológica em curso, preparando recursos humanos para participar de uma economia integrada nos âmbitos continental e mundial, e de um mercado de trabalho competitivo e excludente, ${ }^{2}$ processos estes que vêm aprofundando a dualização social. A reforma procurou também adequar o sistema de ensino espanhol à realidade continental, tendo em vista a iminência da homologação de títulos acadêmicos na União Européia. Neste processo, a EPA, que até então ocupava um espaço reduzido e marginal no sistema educativo e era marcada por um caráter estritamente compensatório, foi objeto de uma profunda e ainda inconclusa reestruturação.

\section{Antecedentes históricos}

Os primeiros registros legais relacionados à EPA na Espanha remontam à transição do século XVIII ao século XIX. Marcado pelo embate político e cultural entre o liberalismo, a restauração monárquica e os movimentos operários nascentes, o séc. XIX caracterizou-se pela alternância de períodos cons- 
titucionais e retrocessos ao absolutismo e pelo descontínuo processo de secularização de uma sociedade abalada pela perda do império colonial.

Sob influência da Revolução Francesa e inspirados pelo lluminismo, os liberais reformistas colocaram no centro de suas propostas a instrução pública como instrumento de progresso econômico e cultural, postulando uma educação elementar comum, com ênfase nos saberes técnicos. Naqueles lapsos de tempo em que a monarquia conviveu com o regime constitucional e nos quais os liberais tiveram ascendência política, prevaleceu o ideário reformista, tendo início a transferência da educação das mãos da Igreja para o Estado e certa expansão do ensino público. Já em princípios do século XIX a instrução pública foi declarada direito universal em qualquer idade. A Lei de Instrução Primária de 1838 atribuía ao governo a conservação e fomento das escolas de adultos, às quais deveriam dirigir-se aqueles que tivessem superado a faixa etária dos 6 aos 13 anos. Em 1857, a Lei Moyano instituiu o ensino obrigatório dos 6 aos 9 anos de idade, gratuito nas escolas públicas, fomentando a educação de adultos em período noturno e aos domingos.

As contendas entre as correntes liberal e conservadora (identificada com os interesses confessionais) e, mais tarde, os movimentos operários e camponeses não se restringiram a influir sobre as políticas de Estado, fazendo-se presentes também nas práticas que desenvolveram no âmbito da sociedade civil.

Submetidas à hegemonia cultural da Igreja, aliada da monarquia absoluta, as universidades resistiram à difusão do ensino científico e laico,sendo necessário que os liberais construíssem novas instituições educativas para promover a renovação educativa pretendida: criaram-se institutos, ateneus e as Sociedades de Amigos do País; estas últimas promoviam tertúlias e assembléias noturnas que foram sendo formalizadas em academias com horários e currículos de formação geral e profissional definidos, nas quais também se ministrava o ensino da lecto-escritura para operários, jovens e adultos pobres.

A restauração absolutista de 1874 suprimiu a liberdade de ensino instituída pela revolução de 1868, o que resultou na expulsão de alguns acadêmicos das universidades. Esses intelectuais liberais constituíram a Instituição de Livre Ensino a qual, embora tivesse caráter universitário, promovia cursos rápidos de divulgação científica dirigidos às camadas populares e foi matriz de uma diversidade de experiências de difusão de uma educação laica e popular, como a Associação para o Ensino da Mulher, o Museu Pedagógico, a Junta para Ampliação de Estudos e as Universidades Populares. 
A emergência do sindicalismo operário e, em seu interior, das correntes anarquistas e socialistas, fomentou no final do século XIX a constituição das primeiras escolas operárias, casas do povo e ateneus populares, aos quais a Igreja Católica respondeu - especialmente após a difusão da Encíclica Rerum Novarum - com a criação de academias cívicas gratuitas para trabalhadores, escolas dominicais e noturnas vinculadas aos Patronatos da Juventude Operária e aos Círculos Operários de Assistência e Educação.

Durante o século XIX, a educação de adultos em escolas públicas teve por objetivos prover ou completar a escolarização básica e profissional da população jovem, e caracterizou-se pela transposição dos conteúdos, materiais e métodos da educação primária destinada às crianças. O precário ensino noturno ou dominical era ministrado por professores voluntários ou sub-remunerados, cansados e desmotivados como seus alunos. O número de escolas para adultos era reduzido e sua expansão obedeceu a um ritmo lento (Quadro I).

A população espanhola chegou ao final do século XIX com índices de instrução inferiores à maior parte dos países europeus, especialmente entre as mulheres, já que a co-educação só seria praticada após 1932 e o número de escolas femininas era reduzido (Quadro II).

Lorenzo Luzuriaga, renovador da educação de princípios do século XX, demonstrou que, menos que os fatores socioculturais, a insuficiência da oferta escolar e sua desigual distribuição constituíram os fatores decisivos na explicação do analfabetismo na Espanha. Sua tese viria a confirmar-se no transcorrer deste século, em que a progressiva difusão do ensino básico facultou a drástica redução do analfabetismo (Quadro III).

\section{O desenvolvimento da educação de adultos ao longo do século XX}

$\mathrm{Na}$ aurora do século $\mathrm{XX}$, em que partidos liberais e conservadores alternaram-se no poder sob o reinado de Alfonso XIII, a monarquia - fragilizada por sucessivas crises político-econômicas, insurreições militares e derrotas no estrangeiro - tinha necessidade de impor-se aos nacionalismos catalão e basco e à agitação popular com um projeto único de nação, e recorreu à educação como instrumento de coesionamento social. A prioridade conferida à educação pelas oposições republicana e socialista e a convergência de seus ideais pedagógicos somaram-se para favorecer o desenvolvimento do sistema educativo espanhol. À margem do sistema oficial de ensino, a intensa atividade educativa promovida pelos anarquistas no meio operário como a Escola Moderna e a Universidade Popular de Ferrer e Guardia - re- 
presentou um impulso adicional à instrução popular. Neste período, a educação de adultos foi consolidando-se como direito e ganhando progressiva institucionalidade mediante leis e decretos que instituíram escolas noturnas e dominicais gratuitas, abonaram os salários dos educadores que a elas se dedicassem e normatizaram seu ensino. ${ }^{3}$ A participação dos jovens e adultos cresceu frente às oportunidades de educação geral e profissional que se abriram, favorecida por conquistas sindicais como a regulamentação da jornada de trabalho (obtida após a greve de 1919), a redução da jornada diária de trabalho dos estudantes com menos de 18 anos de idade e pela abertura de mais escolas femininas. Desse conjunto de medidas, resultou uma escolarização compensatória de adultos em centros educativos públicos, em duas modalidades: escolas cujos professores dedicavam-se exclusivamente à população adulta, e classes de adultos em horário noturno ou durante o inverno nas escolas que atendiam crianças; ambas padeciam da inadequação dos conteúdos, métodos e materiais educativos, que geralmente reproduziam as práticas da educação infanto-juvenil. Em certos casos, a instrução elementar era complementada por algum tipo de capacitação profissional segmentada pelo gênero: artes e ofícios industriais ou técnicas comerciais para homens, culinária, puericultura, costura, enfermagem, datilografia e taquigrafia para as mulheres.

Os pequenos avanços obtidos nas duas primeiras décadas do século estancaram durante a ditadura de Primo de Rivera (1923-30). O grande impulso à democratização da educação aguardaria a Segunda República (1931-36) e seria liderada pelos instituicionistas - denominação pela qual ficaram conhecidos os intelectuais vinculados à Instituição de Ensino Livre, que serviu de modelo à educação republicana de nível médio e universitário. A tarefa de edificação de uma educação primária universal e laica - fazendo frente aos 600 mil alunos atendidos pelas congregações religiosas em um país em que $40 \%$ das crianças estavam fora da escola e $44 \%$ da população era iletrada -, implicaria a criação de 27 mil novas escolas, quando os recursos disponíveis só permitiam atender a um terço dessa demanda. A saída materializou-se na retomada das Missões Pedagógicas criadas em 1922, uma exaustiva campanha de educação popular que alcançou zonas rurais de menor desenvolvimento socioeconômico, combinando atividades voltadas à educação primária de crianças e adultos, educação secundária, formação de professores, formação cívica e animação sociocultural. Aos adultos as Missões dirigiam práticas de alfabetização e difusão cultural - conferências, bibliotecas e museus itinerantes, teatro, cinema e música - inspiradas nas experiências de educação informal promovidas pelos socialistas nas Casas do Povo. 
O período republicano foi marcado por acentuada instabilidade política gerada pela oposição da Igreja e das forças armadas, as questões regionais e sociais irresolvidas - como as reivindicações por autonomia da Catalunha e País Basco ou a reforma agrária - e pela crescente radicalização política à direita e à esquerda, esta última embalada por um movimento anarcosindicalista ascendente e explosivo. A tensão crescente resultou na sublevação militar que conduziu à Guerra Civil (1936-39), durante a qual as regiões controladas pelos republicanos foram alvo de ações educativas dirigidas aos jovens e adultos com forte conteúdo antifascista: dentre outras iniciativas, em 1936 foi criado um bacharelado em dois anos para jovens nos Institutos de Operários, visando preparar rapidamente trabalhadores para ocupar os postos vacantes devido à guerra; em 1937 constituíram-se as Milícias de Cultura, para alfabetizar os efetivos em combate e, na retaguarda, as Brigadas Contra o Analfabetismo, dirigidas à população rural.

A derrota republicana desembocou na longa ditadura do general Francisco Franco (1939-75). O regime ditatorial tratou de apagar os vestígios da cultura republicana, restabelecendo a influência da Igreja, suprimindo a co-educação, o laicismo e o ensino das línguas nacionais, censurando livros e impondo severa vigilância aos intelectuais e professores, muitos dos quais tiveram que exilar-se do país. A Lei do Ensino Primário de 1945 ampliou o ensino elementar até os 12 anos, mas sua obrigatoriedade não resultou em universalização, posto que o franquismo atribuía ao Estado um papel subsidiário aos setores privado e confessional na oferta de serviços educacionais, o que acentuou a seletividade no sistema.

Sob o lema "Espanha não consente analfabetos", a Junta Nacional Contra o Analfabetismo tornou obrigatório a partir de 1950 o ensino primário dos adultos e distribuiu prêmios aos professores que obtivessem melhores resultados (a bonificação aos alfabetizadores implicava que os alfabetizandos dirigissem uma carta de agradecimento ao caudilho pela benesse!). Essa educação compensatória de adultos assumiu os conteúdos (e quase sempre também os métodos) do ensino elementar comum. Nas zonas rurais e regiões menos desenvolvidas promoveram-se escolas de temporada e missões educativas. Em 1954 o ensino de adultos foi reorganizado em quatro modalidades: alfabetização, ensino elementar supletivo, ampliação cultural e iniciação profissional.

O surto desenvolvimentista experimentado pela Espanha nos anos 60 passou a requerer maior qualificação da mão de obra. Em 1963 o governo franquista iniciou nova Campanha Nacional de Alfabetização, envolvendo 
o Exército e outras instituições públicas, privadas e confessionais: cinco mil novas escolas foram criadas e professores rapidamente treinados. O recrutamento dos analfabetos para a Campanha foi marcado por fortes componentes coercitivos, como a imposição de restrições burocráticas ao crédito, a benefícios sociais e dificuldades de acesso a documentos oficiais aos que dela não participassem. A partir de 1968 os recursos dedicados à Campanha foram sendo reduzidos, até que em 1973 ela foi suspensa, mesmo que o contingente de analfabetos tenha diminuído apenas $5 \%$ na década.

$O$ analfabetismo foi combatido sob o franquismo como um cancro social a ser extirpado. A educação de adultos foi encarada como uma dádiva do Estado, obrigação e não direito do cidadão. Os objetivos de difusão da ideologia nacional-católica franquista precediam os fins pedagógicos e as estatísticas de alfabetização (mesmo falseadas) sobrepuseram-se aos efetivos resultados da aprendizagem, de modo que a Campanha teve reduzido impacto sobre a elevação do nível cultural da população.

No final dos anos 60, o déficit escolar espanhol situava-se em torno de um milhão de vagas e a defasagem do sistema educativo em relação a outros países europeus repercutia negativamente sobre a economia do país. A tentativa de promover uma reforma estrutural do sistema educativo, tendo em vista inserir os migrantes rurais no ambiente urbano e qualificar mão-deobra e, ao mesmo tempo, responder à opinião pública externa e às pressões da UNESCO, resultou em 1970 na Lei Geral de Educação, que conferiu um marco jurídico mais estável à EPA. Um decreto ministerial de 1973 desencadeou o Programa de Educação Permanente de Adultos que, em substituição à extinta Campanha, patrocinou a criação de novos centros, regulou a obtenção do diploma de graduado escolar (correspondente ao ensino elementar obrigatório) e propôs alguns lineamentos pedagógicos específicos. Essas medidas facultaram uma ação compensatória mais efetiva, mediante a ampliação do número de centros e professores especialmente dedicados, embora não tenham rompido o modelo rígido e formal dominante e a histórica subordinação dos currículos da educação de jovens e adultos aos parâmetros da educação infantil. Uma renovação mais profunda das políticas de formação de adultos teria que esperar a redemocratização do Estado espanhol.

\section{A EPA na transição à democracia}

Com a morte de Franco em 1975, coube ao Rei Juan Carlos enfrentar as pressões internas e externas pela democratização do regime e conduzir 
a transição política, pactada após anistia, convocação da Constituinte e referendo popular. O período de transição democrática (1977/82) foi marcado por uma verdadeira explosão de participação e de demandas sociais reprimidas, dentre elas as reivindicações por oportunidades de formação para pessoas adultas, às quais o governo respondeu precariamente, criando novos centros educativos e agregando horas noturnas à jornada semanal de trabalho dos professores que ensinavam crianças e adolescentes durante o dia. ${ }^{4}$

As eleições parlamentares de 1982 deram a vitória ao Partido Socialista Operário Espanhol (PSOE), que permaneceu no poder pelos 14 anos seguintes. Reconhecendo a existência de mais de 2 milhões de analfabetos absolutos e quase 11,5 milhões de analfabetos funcionais, o governo emitiu em 1983 - Decreto de Educação Compensatória que desencadeou medidas de descentralização, propiciou maior articulação entre os organismos de educação e trabalho e favoreceu o desenvolvimento de experiências alternativas de EPA. Em 1985, a Lei Orgânica do Direito à Educação promoveu mudanças urgentes em aspectos do sistema educativo herdados do franquismo. Pressionado pelos movimentos de renovação pedagógica e pelos organismos de cooperação européia, o governo socialista deu início, então, à reforma educativa. O Serviço de Educação Permanente de Adultos do MEC elaborou para discussão uma primeira versão de uma plataforma para uma futura Lei de Educação de Adultos, que ficou conhecida como o Libro Verde; sua reformulação mediante ampla consulta resultou, em 1986, no Libro Blanco que, nos marcos da educação permanente, fixou as diretrizes para a reforma da EPA ${ }^{5}$ nos anos seguintes: conferir caráter integral à educação, articulando o âmbito educativo ao meio social e à experiência pessoal e profissional dos educandos; integrar as dimensões de formação geral básica, para o trabalho, para o desenvolvimento pessoal, a participação social e cultural; adotar um desenho curricular próprio, modular e flexível; articular as modalidades de ensino presencial e a distância; adotar a referência territorial como unidade espacial de planejamento e oferta educativos, mediante a coordenação de recursos materiais, humanos e técnicos e a cooperação intra e inter-institucional de organismos públicos, entidades privadas e comunitárias de educação, saúde, cultura, emprego e meio ambiente; promover a descentralização e a divisão de competências entre as esferas de governo. Esses princípios foram incorporados em 1990 à Logse, cujo capítulo dedicado à EPA procura conciliar eqüidade e flexibilidade no intuito de acolher a diversidade sociocultural, de estilos cognitivos e biografias formativas que caracteriza a população demandatária.

Enquanto a nova lei tramitava no parlamento, uma ordem ministerial de 1989 conferiu aos centros públicos de EPA vinculados ao MEC o papel 
de coordenadores das atividades públicas e privadas neste campo educativo em seu âmbito territorial, o que ajudou a consolidar essa rede mediante ampliação do quadro de pessoal, melhorias na infra-estrutura e diversificação da oferta.

Alguns segmentos reivindicavam uma lei específica de formação de adultos para toda Espanha, o que não ocorreu, pois a Constituição de 1978 - respondendo às demandas das nacionalidades históricas - consagrou a descentralização do Estado, criando comunidades autônomas, às quais vêm sendo transferidas as competências em matéria de atenção educativa, preservando o Estado espanhol as funções de normatização do ensino e regulação das condições de expedição de certificados. Ao longo dos anos 90, Valência, Catalunha, País Basco, Galícia, Andaluzia e Canárias habilitaram-se a prover autonomamente os serviços educativos, votando suas respectivas leis de EPA.

\section{Influências dos contextos europeu e internacional}

As Conferências Mundiais de Educação de Adultos convocadas pela Unesco - desde a de Elsinore, em 1949, até a de Hamburgo, em 1997- têm influenciado as concepções e práticas de educação de adultos em todo o mundo; na Espanha, esse tipo de influência adquiriu relevância a partir da queda do regime franquista. No início dos anos 80 , a influência de organismos multilaterais europeus e os influxos da XIX Conferência Geral da Unesco de Nairobi (1976) parecem ter sido decisivos para impulsionar mudanças na EPA espanhola.

Em fins dos anos 70, o Conselho da Europa deu início a uma série de reuniões ${ }^{6}$ que marcaram a transição do paradigma compensatório em direção a uma nova concepção de educação continuada, cujo intento é superar o marco escolar e a concepção de formação que dissocia estudo e trabaIho, colocando-os em seqüência descontínua no tempo. Frente ao novo contexto - marcado pela mundialização da economia, crescente valorização da informação e do conhecimento, transformações no mundo do trabalho e intensificação da dualização social - o novo paradigma de educação continuada de pessoas adultas procura informar políticas educativas apoiadas nos princípios de integração (ao qual corresponde uma maior articulação da educação à vida cotidiana, seja no trabalho ou fora dele), de participação (ao qual corresponde uma formação integral voltada para a participação do indivíduo nas dimensões política, econômica e cultural da vida social), e de eqüidade (que propõe superar os obstáculos para que pessoas de distintas classes, gêneros, idades e etnias tenham acesso às oportunidades educativas). 
Em 1981 a Organização para a Cooperação e o Desenvolvimento Econômico (OCDE) deu início a uma análise do sistema educativo espanhol que diagnosticou rigidez e tradicionalismo dos métodos de ensino, inadequação da oferta às necessidades educativas da população jovem e adulta, insuficiência dos recursos materiais alocados, falta de profissionalismo no desenvolvimento deste âmbito educacional, escassez de pesquisa aplicada, falta de articulação entre os ministérios e outros organismos públicos e privados, bem como sub-aproveitamento dos recursos comunitários potencialmente disponíveis. Na segunda metade da década de 80 a Espanha foi incorporada ao Programa 9 do Conselho Europeu -- Educação de Adultos e Desenvolvimento Comunitário - e, até que o programa fosse extinto em 1990, os recursos do Fundo Social Europeu subsidiaram a constituição da Rede de Iniciativas Locais e Desenvolvimento Comunitário e o desenvolvimento de um programa de renovação pedagógica nos centros públicos de EPA.

Desde que ingressou na Comunidade Européia em 1986, o influxo europeu $^{7}$ tem impelido a Espanha a rever a rigidez e o formalismo da formação de adultos no sistema oficial de ensino, conferir valor à educação informal, reconhecer as aprendizagens extra-escolares e integrar a educação geral à formação profissional. Neste final da década de 90 , a auto-imagem da Espanha integrada à "Europa dos Quinze" é a de uma sociedade pósindustrial e informacional que deve responder aos desafios da mundialização econômica e da revolução técnico-científica com um sistema de educação ao longo de toda a vida a que fazem referência tanto os documentos da Comissão Européia como os da Unesco.

\section{Os movimentos de renovação pedagógica da EPA}

Nos extertores da ditadura, enquanto o ensino público permanecia impermeável às demandas de democratização que se gestavam na sociedade espanhola, floresceram por iniciativa de organizações civis movimentos inspirados no pensamento freireano ou cristão progressista e influenciados pelas experiências francesa de desenvolvimento sócio-comunitário ou latino-americana de educação popular. As Universidades Populares, cuja origem remonta ao final do séc. XIX e que haviam sido extintas durante a ditadura franquista, ressurgiram no final dos anos 70 por iniciativa social, ganhando impulso na década seguinte graças ao apoio de administrações locais progressistas que chegaram ao poder pela via eleitoral. Em 1982 constituise a Federação das Universidades Populares, cujo número se multiplica continuamente, chegando a alcançar a cifra de 90 no início da década de 1990. 
Enquanto isso, em Ávila, ao norte do país, experiências que combinavam atividades educativas, culturais e cooperativas econômicas inauguraram o movimento das Escuelas Campesinas, que se estenderia a outras regiões espanholas. Desde os primeiros anos da redemocratização multiplicaramse também nas periferias das grandes cidades industriais iniciativas comunitárias de EPA impulsionadas por associações de moradores, que receberam a denominação de Escuelas Populares. Estas iniciativas foram articulando-se em coletivos, coordenações e associações, congregadas em sua maioria pela Federación de Asociaciones de Educación de Adultos (FAEA) que alcança todo o território espanhol.

Pautados pelo princípio de respeito à diversidade de experiências, estes organismos associativos de EPA foram constituindo uma plataforma mínima de unidade político-pedagógica, ampliada e renovada nas jornadas que promovem periodicamente. Eles cumprem múltiplas funções: propiciam o intercâmbio de experiências, fomentam a produção e distribuição de publicações e materiais didáticos, elaboram concepções de formação e promovem cursos de especialização de educadores, formulam demandas e propostas aos poderes legislativo e executivo, incidindo sobre as políticas públicas. Influenciados pelo novo paradigma emergente, os movimentos de renovação pedagógica pressionam para que as políticas públicas incorporem inovações de duas ordens: em busca de maior eqüidade, propõem políticas ativas de supressão de obstáculos à participação dos adultos em processos formativos, mediante escolarização gratuita, flexibilidade curricular e de horários, diversificação dos espaços e meios de ensino, reconhecimento das aprendizagens adquiridas informalmente na experiência sócio-laboral e discriminação positiva em relação aos grupos com maiores dificuldades de acesso e progressão no sistema educativo (mulheres, ciganos, imigrantes, portadores de deficiências etc.); com os propósitos de integração e participação, concebem o distrito como unidade territorial do planejamento e gestão descentralizada dos serviços, de modo a coordenar recursos materiais e humanos de diferentes fontes e conformar uma rede educativa indissociada da vida comunitária cotidiana.

\section{Superando a concepção compensatória de EPA}

Quando o MEC emitiu em 1987 o primeiro projeto de reforma do ensino, o texto referente à EPA reproduzia a tradicional concepção que atribui as necessidades educativas atuais da população adulta a deficiências passadas do sistema educativo, a serem sanadas mediante escolarização compensatória para aqueles que a ela não tiveram acesso na "idade apropriada": 
Como fundamento esencial de todas ellas, la formación general o de base que, cuando no se consiguió en la edad apropiada, constituye un requisito indispensable de tipo compensador" (MEC, 1987, p. 32). Essa concepção levava o governo a interpretar que as necessidades sociais de EPA tenderiam a declinar com a implantação da reforma, permitindo-lhe priorizar a população jovem que não havia concluído a escolaridade obrigatória. Os movimentos de renovação reagiram a tais análises e políticas, argumentando não haver idade adequada para a formação e que a própria reforma iria ampliar as necessidades sociais de EPA em razão do efeito desnivelador (Flecha, 1990) desencadeado pela elevação da escolaridade mínima obrigatória (Quadros IV).

Os dados demonstravam que, ainda que a reforma superasse totalmente o fracasso escolar, o efeito desnivelador não se restringiria aos grupos de idade mais avançada, mas seria patente também na população adulta jovem, economicamente ativa, responsável pela socialização e êxito escolar das novas gerações (Quadro V).

Em 1989 o projeto final da reforma superou a visão compensatória, admitindo que a atual evolução da sociedade requer da população adulta níveis crescentes em extensão e amplitude de educação básica.

\section{A formação dos educadores}

Os profissionais dedicados à EPA na Espanha provêm da formação universitária comum ao professorado do ensino básico, cursada nas Escolas de Magistério e Institutos de Ciências da Educação, ou da carreira de Educação Social .

Além de uma formação inicial de qualidade, os educadores espanhóis que atuam no sistema público de ensino dispõem de uma ampla gama de oportunidades de formação permanente. Os sistemas de ensino das comunidades autônomas e províncias dispõem desde 1984 de uma rede de centros de formação permanente do professorado que respondem por programas plurianuais de aperfeiçoamento realizados com apoio das universidades públicas, provêm orientação pedagógica, elaboram recursos didáticos, desenvolvem pesquisas educacionais e fomentam o desenvolvimento curricular. A formação inicial e em serviço dos educadores freqüentemente é acrescida de especializações em nível de master. ${ }^{9}$ As universidades e fundações de formação de professores mantêm uma extensa oferta de cursos de aperfeiçoamento para educadores de adultos que atuam na educação geral ou profissional, em sua maioria promovidos em convênio com associações de EPA. 
Apesar dessa multiplicidade de ofertas, os estudiosos do tema consideram que a formação dos educadores dedicados à EPA na Espanha é insuficiente e não tem um projeto acabado para tratar as especificidades dessa modalidade educativa.

\section{Configuração atual da EPA}

Não é fácil delinear o perfil atual da EPA na Espanha, uma vez que a reforma educativa ainda está em implantação e verifica-se certa heterogeneidade regional além de uma tendência à diversificação de fins, meios e modalidades formativos. Sinteticamente, pode-se afirmar que integramse em uma densa e complexa rede os sub-sistemas de formação geral e profissional, uma multiplicidade de cursos livres e oportunidades de educação informal.

Embora seja bastante flexível e comporte experiências inovadoras, a formação geral básica apresenta de forma mais acentuada elementos de continuidade herdados do passado. Trata-se de oferta pública formal, que dá continuidade ao antigo Programa de Educação Permanente e cumpre explicitamente a função compensatória de prover a escolaridade mínima obrigatória equivalente à EGB e o respectivo diploma de graduado escolar. Desenvolve-se mediante ensino presencial em equipamentos escolares específicos - os Centros de Formação Permanente de Pessoas Adultas (em 1991 somavam 1.912), ou por ensino à distância, utilizando recursos da Rádio ECCA (das Ilhas Canárias) ou da televisão (nas Comunidades de Madri e Catalunha), com apoio de materiais didáticos impressos e recepção organizada em centros especialmente destinados a esse fim (eram 78 em 1987).

A Logse, porém, elevou a escolaridade mínima obrigatória e seu cronograma de implantação prevê que entre 1998 e 2002 seja universalizada a ESO, o que vem sendo assegurado à população juvenil no sistema público de ensino. Colocou-se assim mais um degrau de desnivelamento a ser superado por uma EPA ampliada. Como a legislação espanhola assegura a todos cidadãos eqüidade de acesso ao ensino básico, esperavase a abertura da ESO nos centros públicos de EPA em 1998, o que não ocorreu, motivo pelo qual os movimentos de educação permanente vêm desencadeando intensa mobilizaçao. ${ }^{10}$

A reforma do sistema de formação profissional teve início em 1985 e consolidou-se em 1989 no 1ํ Plano Nacional de Formação e Inserção Profissional, cujos objetivos eram a integração entre as políticas de formação 
e emprego, a modernização dos conteúdos da formação e a atenção prioritária aos grupos desfavorecidos no acesso ao mercado de trabalho.

Em 1990 a Logse reordenou a formação profissional, que passou a permear todos os níveis do sistema de ensino. Os currículos da educação básica (EGB e ESO) passaram a compreender uma formação tecnológica geral e polivalente. A formação profissional stricto sensu desenvolve-se em ciclos de organização modular e duração variável, ordenados por áreas de conhecimento teórico-práticas nos diversos campos profissionais. A formação técnica de grau médio é uma alternativa de estudos pós secundários (Módulos de Nível II) e a ela se segue a formação profissional de ciclo superior (Módulos de Nível III), provendo ambas certificação técnica equivalente às qualificações de nível Il e III padronizadas para a Comunidade Européia. Os jovens e adultos sem titulação prévia podem aceder diretamente à formação profissional de nível médio (Módulo II) a partir dos 17 anos, ou de nível superior (Módulo III) a partir dos 20 anos, se aprovados em exames de equivalência. A formação técnica superior faculta o acesso à universidade nas carreiras relacionadas à respectiva profissão. A Logse também permite aos adultos com mais de 25 anos o acesso à universidade sem titulação prévia, mediante aprovação em exames específicos.

O Instituto Nacional do Emprego responde pela formação continuada dos trabalhadores, pela inserção e reinserção dos desempregados no mercado de trabalho. $O$ Inem oferece aos desempregados ou aos empregados (em convênio com as empresas) uma infinidade de oportunidades de atualização, requalificação e reconversão profissional.

Convênios recentes entre os órgãos de emprego, educação e assistência propiciaram a implantação de um programa especial que associa formação geral e profissional, denominado "garantia social", dirigido a jovens de 16 e 20 anos que não obtiveram o certificado da EGB.

Embora os números relativos ao investimento e às pessoas beneficiadas sejam de magnitude considerável, há evidências de que o sistema de formação e inserção profissional tem reduzida capacidade de influenciar a dinâmica excludente do mercado de trabalho, e ainda não se dispõe de estudos avaliativos para aferir a sua eficácia global.

\section{Observações finais}

O balanço das políticas recentes de EPA na Espanha apresenta resultados positivos nos aspectos relacionados à democratização do acesso, 
consolidação de um novo paradigma de educação continuada, implicação dos organismos não governamentais, maior descentralização e coordenação estrutural entre as esferas e órgãos de governo. Alguns analistas avaliam que há tarefas pendentes na consolidação de um marco legislativo para todo o país e no desenho de uma política de formação de formadores. Outros, observam que a dualização social vem reproduzindo e introduzindo novos mecanismos de seleção e exclusão educacional. ${ }^{11}$ Há consenso, porém, em que a explosão de participação em processos formativos na Espanha (Quadro VI) é resultado da transição para uma economia pós industrial e uma sociedade informacional, que engendram novos requisitos cognitivos para a participação das pessoas adultas nas diferentes esferas da vida social.

\section{Notas}

1. O ensino básico espanhol regulado pela Logse compreende uma educaçao obrigatória de dez anos (que antecede a formação técnica, pré-universitária e universitária) subdividida em duas etapas: a Educação Geral Básica (EGB), com seis anos de duração (dos 6 aos 12 anos) e a Educação Secundária Obrigatória (ESO) com quatro anos de duração (dos 12 aos 16 anos).

2. A Espanha apresenta os pioes indicadores de emprego da UE: a taxa de ocupação é de $32 \%$ na população total e 61\% entre aqueles com idade de 16 a 64 anos; 0 desemprego atinge $19,9 \%$ das 15,5 milhões de pessoas da PEA atinge especialmente jovens, mulheres e desempregados de longo prazo; $8 \%$ dos empregados trabalham em tempo parcial. A flexibilização das relações de trabalho ampliou os contratos temporários e gerou maior instabilidade no emprego.

3. A norma previa dois períodos letivos de alfabetização e pós-alfabetização com cinco meses de duração cada, e duas horas diárias de aula em classes de até 40 alunos

4. Em 1979 esse adicional foi incorporado ao salário e muitos educadores deixaram as classes noturnas. Desde então, a dificuldade de contratação de professores tem sido objeto de contínuos movimentos das associações`de EPA.

5. Consideram-se pessoas adultas aquelas com mais de 16 anos cuja ocupação principal não é ser estudante.

6. A literatura destaca as reuniões de Estocolmo (1975), Siena (1979) e Estrasburgo (1986).

7. A União Européia promoveu outras quatro reuniões sobre educação de pessoas adultas: Atenas e Dresden, 1994; Madri, 1995; Iorença, 1996.

8. O Magistério tem 3 anos de duração e habilita ao ensino do pré-escolar aos 14 anos; a habilitação plena nos ICEs dura quatro anos (ou um ano adicional pós-magistério) e faulta ensinar também no $2^{\circ}$ ciclo da ESO. A Educação Social não tem correlato no Brasil; destina-se a preparar educadores para os serviços de atenção a idosos, 
portadores de deficiências, imigrantes, dependentes de drogas etc., formando profissionais que atuam na educação informal, na animação sociocultural e de tempo livre.

9. O master é uma especialização pós-universitária realizada em cursos de duração variável e corresponde ao mestrado lato sensu brasileiro; a pós-graduação stricto sensu na Espanha realiza-se em nível de doutorado.

10. Na Catalunha, por exemplo, apenas dois centros de EPA implantaram a ESO em 1998 e o governo não elaborou o mapa escolar (instrumento pelo qual se avalia a demanda e se planeja a oferta pública), atividade à qual está obrigado por lei. Os movimentos de EPA promoveram em Barcelona em fevereiro uma imensa manifestação reivindicando a abertura de ESO, a elaboração do mapa escolar e um plano de capacitação dos professores; os manifestantes entregaram ao Parlamento uma petição subscrita por 44 mil cidadãos e 460 entidades sociais, culturais e educativas. A repercussão do protesto impeliu a oposição a propor uma moção de censura ao governo, aprovada por ampla maioria dos deputados, o que obriga a rever sua política.

11. As pessoas mais jovens, com maior escolaridade e melhor posicionamento no mercado de trabalho são as que mais desfrutam das oportunidades de educação continuada (Quadro VII). O investimento na EPA é crescente mas se concentra na formação profissional em detrimento da educação geral ou sociocultural.

Recebido para publicação em Janeiro de 1999.

\section{Recent evolution of adult education in Spain}

ABSTRACT: The paper reports the development of adult education in Spain from its early stages in the $19^{\text {th }}$ century to present days. Emphasis is given to innovations introduced in the 80's by the teaching reform, wich was consolidated in 1990 by the General Organization Law of the Teaching System. Influences on this process from the pedagogical renovation movements as well as from international and multilateral european organizations are analyzed. Among the innovations analyzed, the following are highlighted: adult education conceived as a paradigm of continuous education rather than the compensatory trait that historically had guided it; decentralization of education favoring Autonomous Communities; integration as a preeminent political and pedagogical principle; territory adopted as a planning unit for educational availability.

\section{Bibliografia}

BORJA, Antón. "Educación de adultos y estrategias de formación continua: los casos español y vasco". Donostia, set. 1997, 35p. (paper apresentado no Congreso de Formación de Personas Adultas del País Vasco). 
CABELLO MARTíNEZ, María Josefa. "Modelo didáctico de educación de adultos". Tese de doutoramento. Madri, Universidade Complutense de Madrid, 1992, 433p.

CREA. Participació i no participació en la formació de persones adultes a Catalunya. Barcelona, 1996, $102 \mathrm{p}$.

CREA. "Transition towards lifelong learning in Spain". Comparative Studies on Lifelong Learning Policies: Report of a NIER/UIE joint research project. Tóquio: NIER, UIE, 1997, pp. 203-219.

DELORS, Jacques (coord.). La educación encierra un tesoro. Madri: Unesco/ Santillana, 1996.

DIÁZ GONZÁLEZ, Tomáz. "Política del Ministerio de Educación y Ciencia en temas de educación de adultos (1970-1990)". In: REQUEJO OSORIO, Agustín (coord.). Política de educación de adultos. Santiago de Compostela: Tórculo, 1994, pp. 81-112.

EUROPEAN COMMISSION. Growth, Competitiveness, Employement. Bruxelas: European Union, 1993.

FLECHA, Ramón. La nueva desigualdade cultural. Barcelona: El Roure, 1990, pp. 132-133.

FLECHA, Ramón; GÓMEZ, Aitor. " A educação de adultos rumo ao século XXI: perspectivas face à $V$ Confintea. Barcelona, 1996, 8p. (inédito).

FLECHA GARCÍA, Ramón; LOPES PALMA, Fernando; COYA, Raquel Saco. Dos siglos de educación de adultos: De las Sociedades de Amigos del País a los modelos actuales, $2^{\underline{a}}$ ed. Barcelona, El Roure, 1994.

GARCÍA DE CORTÁZAR, F.; GONZÁLEZ VEGA, J.M. Historia de España. Madri: Alianza, 1994, 93p.

GUÍA del Mundo 1996-1997: El mundo visto desde el Sur. Montevideo: Madri, ITM: lepala, 1997.

JABONERO BLANCO, M.; NIEVES CAZORLA, María R.; RUANO MORCUENDE, María I. Educación de personas adultas: um modelo de futuro. Madri: Muralla, 1997, 142p. (Colección Aula Abierta)

LLEI de formació d'adults de Catalunya [Lei 3/1991, de 18 de març de formació d'adults]. Barcelona, Generalitat de Catalunya/Departament de Benestar Social, 1996, 63p.

LIBRO Blanco de la Educación de Adultos. Madri, MEC, 1986. 
MORENO MARTÍNEZ, Pedro L.; VIÑAO FRAGO, Antonio. "La educación de adultos en Espana (Siglos XIX-XX): Historia de una realidad cambiante y multiforme". In: GARCÍA CARRASCO, Joaquín (coord.). Educación de adultos. Barcelona: Ariel, 1997, pp. 23-46.

PLA local d'educació d'adults. Barcelona, Diputació de Barcelona/Area de'Educació, maig 1994, 16p. (Collecció Guies Metodològiques)

PNUD. Informe sobre el desarrollo humano 1993. Madri: Cideal, 1993.

REQUEJO OSORIO, Agustín. Política de educación de adultos en Espana. In: Política de educación de adultos, cap. 1. Santiago de Compostela, Tórculo, 1994, p. 9-79.

REQUEJO OSORIO, Agustín (coord.). Política de educación de adultos. Santiago de Compostela, Tórculo, 1994, 472 p.

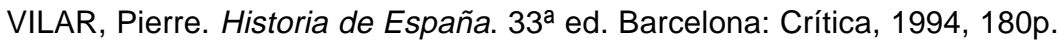

Fontes de imprensa

"Europa busca empleo a 18 millones de parados". Barcelona, El Periódico, 16/11/1997.

"La Generalitat recuerta sus presupuestos para educación de adultos". Barcelona, El Periódico, 2/12/1997.

"La oposición en bloque pide un mapa escolar a la Generalitat". Madrid, El País, 14/2/1998.

"44.000 firmas en favor del mapa de escuelas de adultos". Madrid, El País, 26/2/1998.

"El Parlament descalifica unánimente la política de Comas sobre educación de adultos". Madrid, El País, 27/2/1998.

ESPINET, Alfonso. "Ayuda a jóvenes sin título". Barcelona, Suplemento el Empleo d'El Periódico, 13 a 19/101997, p. 21. 


\section{Anexos}

Quadro I: Evolução da educação de adultos na Espanha entre 1850 e 1933

\begin{tabular}{|c|c|c|c|c|c|c|}
\hline Ano & \multicolumn{3}{|c|}{ Escolas } & \multicolumn{3}{c|}{ Alunos } \\
\hline & Total & Masculinas & Femininas & Total & Homens & Mulheres \\
\hline 1850 & 264 & - & - & - & - & - \\
\hline 1860 & 844 & - & - & 28.949 & 28.626 & 323 \\
\hline 1870 & 1.848 & - & - & - & - & - \\
\hline 1885 & 1.579 & 1.521 & 76 & 65.317 & 61.905 & 3.352 \\
\hline 1903 & 5.533 & 5.431 & 102 & - & - & - \\
\hline 1908 & 11.800 & - & - & - & - & - \\
\hline 1933 & 22.406 & 21.406 & 1.043 & 583.912 & 542.618 & 41.294 \\
\hline
\end{tabular}

Fonte: Moreno Martinez; Viñao Frago, 1997

Quadro II: Evolução do analfabetismo geral na Espanha no séc. XIX

\begin{tabular}{|c|c|c|c|}
\hline Ano & \% Total & \% Masculino & \% Feminino \\
\hline 1860 & 75,52 & 64,9 & 85,9 \\
\hline 1877 & 72,01 & 62,6 & 80,9 \\
\hline 1887 & 68,01 & 58,8 & 76,8 \\
\hline 1900 & 63,78 & 55,7 & 71,4 \\
\hline
\end{tabular}

Fonte: Flecha Garcia; Lopez Palma, 1994.

Quadro III: Evolução do analfabetismo na população com 10 anos ou mais ${ }^{-}$

\begin{tabular}{|c|c|c|c|}
\hline Ano & \% Total & \% Masculino & \% Feminino \\
\hline 1900 & 56,07 & 45,58 & 65,89 \\
\hline 1920 & 42,88 & 34,99 & 50,16 \\
\hline 1940 & 23,17 & 17,28 & 28,46 \\
\hline 1960 & 13,64 & 8,99 & 17,93 \\
1981 & 8,80 & 5,09 & 12,26 \\
\hline 1990 & - & 2,50 & 5,80 \\
\hline
\end{tabular}

Fontes: Flecha Garcia \& Lopez Palma, 1994; Guía Del Mundo 1996-1997. 
Quadro IV: Pessoas com 16 anos e mais e escolaridade inferior à mínima obrigatória

\begin{tabular}{|l|l|l|ll|l|}
\multicolumn{2}{|c|}{1981} & \multicolumn{2}{c|}{1991} & & \\
\hline 10.840 .029 & $38,72 \%$ & 22.982 .522 & $75,29 \%$ & 19.986 .716 & $61,58 \%$
\end{tabular}

Fonte: Flecha; Gómez. 1996

Quadro V: Pessoas com escolaridade inferior à mínima obrigatória

\begin{tabular}{|c|c|c|c|cc|c|}
\hline Idade & $\mathbf{1 9 8 1}$ & $\mathbf{\%}$ & $\mathbf{1 9 9 1}$ & $\mathbf{\%}$ & $\mathbf{2 0 0 0}$ (est) & $\mathbf{\%}$ \\
\hline Total & 10.840 .030 & 38,71 & 22.982 .522 & 75,29 & 19.986 .716 & 61,58 \\
\hline $16-24$ & 622.877 & 10,03 & 3.472 .238 & 59,29 & 0 & 0 \\
\hline $25-44$ & 2.908 .418 & 31,29 & 7.097 .680 & 65,54 & 7.045 .757 & 58,71 \\
\hline $45-64$ & 4.430 .867 & 53,63 & 7.436 .141 & 87,62 & 7.491 .372 & 79,01 \\
\hline $65 \mathrm{e}+$ & 2.877 .868 & 92,97 & 4.976 .463 & 92,97 & 5.449 .587 & 91,21 \\
\hline
\end{tabular}

Fonte: Flecha; Gómez. 1996.

Quadro VI: Matrículas em Educação de Pessoas Adultas - 1991

\begin{tabular}{c|c|c|c|c}
\hline Total & Ed. Geral & \% & Ed. Sociocultural/Laboral & $\%$ \\
\hline 548.913 & 289.557 & 52,75 & 259.356 & 47,24 \\
\hline
\end{tabular}

Fonte: Mec, 1991 Apud Requejo, 1994.

Quadro VII - Participação de Pessoas Adultas em Cursos na Espanha*

\begin{tabular}{|c|c|c|}
\hline \multicolumn{2}{|c|}{ Grupos } & $\%$ \\
\hline \multicolumn{2}{|c|}{ Total } & 14 \\
\hline Faixas etárias & 16 a 18 anos & 19 \\
\hline & 19 a 25 anos & 23 \\
\hline & 25 a 45 anos & 20 \\
\hline Nível de escolaridade & 45 a 65 anos & 8 \\
\hline & universitário & 2 \\
\hline & educação pós obrigatória & 28 \\
\hline & educ. secundária (ESO) & 13 \\
\hline & educ. primária (EGB) & 5 \\
\hline
\end{tabular}

* Participação declarada em curso nos últimos 12 meses. Fonte: CREA, 1996. 